\title{
Planteamiento de una ecuación diferencial lineal de primer orden que modela un problema de mezclas: Una dificultad en la movilización entre registros de representación, lengua natural y algebraico
}

\section{Proposal of a Linear Differential Equation of First Order that Shapes A Mixture Problem: Mobilization Difficulty among Representation Records and Natural and Algebraic Language}

\author{
Luis Alberto Jaimes Contreras ${ }^{1 \star}$, Rafael Felipe Cháves Escobar ${ }^{1 \star \star}$, \\ César Augusto Hernández Suárez ${ }^{2 \star \star \star}$ \\ 1 Universidad Distrital Francisco José de Caldas, Bogotá, Colombia \\ ${ }^{2}$ Universidad Francisco de Paula Santander, Cúcuta, Colombia
}

FeCha De Entrega: 7 DE NOVIEMbre DE 2014

FECHA DE EVALUACIÓN: 16 DE FEBRERO DE 2015

FECHA DE APROBACIÓN: 26 DE FEBRERO DE 2015

\begin{abstract}
Resumen Aunque la noción de ecuación diferencial está presente en campos como las matemáticas e ingeniería, su comprensión por parte de estudiantes y algunos profesores ha sido limitada, debido al enfoque algebraico en el que se ha centrado la enseñanza de las ecuaciones diferenciales, dejando de lado la construcción de la ecuación diferencial (ED), la cual es el fundamento al modelar algunos fenómenos físicos. En este artículo presentamos algunas dificultades identificadas al construir la ecuación diferencial que permite modelar un problema de mezclas en un grupo de 21 estudiantes de una universidad pública inscritos en la asignatura de ecuaciones diferenciales.
\end{abstract}

Abstract Although the notion of differential equation is present in fields such as mathematics and engineering, understanding by students and some teachers has been limited due to the algebraic approach that has focused teaching differential equations, neglecting the construction of

* Magister en Educación Matemática - Universidad Pedagógica Nacional. lajaimesc@udistrital.edu.co

* Magister en Educación Matemática - Universidad Pedagógica Nacional. rafach_25@hotmail.com

$\star \star \star$ Magister en Enseñanza de las Ciencias Básicas - Universidad Nacional Experimental del Táchira (Venezuela). cesaraugusto@ufps.edu.co 
the differential equation (DE), which is the foundation to model some physical phenomena. In this paper, we present some difficulties identified to build the differential equation that models a problem mixing in a group of 21 students enrolled in a public university the subject of differential equations.

Palabras Clave: problema de mezclas, registros de representación semiótica, movilización entre registros, ecuación diferencial.

Keywords: mixing problem, registers of semiotic representation, mobilization between registries, differential equation.

\section{Introducción}

En el plan curricular de los programas académicos de ingeniería el fundamento matemático se encuentra ubicado en la línea del análisis matemático. Un estudiante en su formación como ingeniero en los primeros semestres se enfrenta a asignaturas como cálculo diferencial, cálculo integral, cálculo vectorial y ecuaciones diferenciales. Esta última se encuentra ubicada en semestres avanzados debido a que exige al estudiante una formación sólida y más elaborada en matemáticas. Sin embargo también es el causante de que muchos estudiantes tengan retraso en la asignatura normal de su programa académico.

Desde la experiencia docente en la enseñanza de las ecuaciones diferenciales, se ha observado que los índices de repitencia en la asignatura son elevados, incluso hay periodos en que aumenta pero nunca disminuyen. Una de las razones de que esto suceda se debe a que los estudiantes requieren del manejo adecuado de conceptos fundamentales del cálculo. Las dificultades con las que llegan los estudiantes a esta asignatura son varias, por ejemplo, cuando se les presenta un problema matemático, no reconocen ni diferencian: constantes, parámetros, variables, cambio de una variable respecto a otra; y tampoco son capaces de plantear una ecuación que las relacione.

Según lo señalan [4], en el estudio de las ED, actualmente "predomina el enfoque algebraico como reflejo de la primera forma que se tuvo de resolver problemas que involucran ED" y que algunos docentes hoy en día emplean como estrategia didáctica. Al igual que [5], en la enseñanza de las ED, algunos conceptos relacionados con límite, derivación e integración son evadidos y ocultados con fórmulas o algoritmos, lo cual impide la comprensión precisa del concepto llevando al estudiante, y en ocasiones a los docentes, a concebir la fórmula como un concepto en sí mismo. Incluso en libros de ED, como por ejemplo [6], cuando se abordan los modelos lineales de primer orden por lo general se le da al estudiante la ED que permite modelar este tipo de situaciones, pero no se explica el concepto para que los estudiantes la comprendan; al contrario solo se ofrece la fórmula [5].

El presente escrito tiene como propósito exponer que una de las dificultades de los estudiantes al abordar un modelo lineal de primer orden, como lo son los problemas de mezclas, radica en la movilización del registro de representación de la lengua natural al algebraico o al formal. Para dar cuenta de esto, se presenta una actividad propuesta a estudiantes de ingeniería civil de una Universidad 
Pública que permitió recoger la información que condujo a realizar un análisis de las causales de esta dificultad. Se espera entonces responder la siguiente pregunta orientadora: ¿Cómo cobra sentido la movilización entre el registro de representación lenguaje natural al algebraico en el estudiante, cuando plantea una ecuación diferencial lineal de primer orden que modela un problema de mezclas?

\section{Marco teórico}

El estudio que se expone en este artículo considera como referencia el enfoque cognitivo desarrollado por Raymond Duval [2] basado en los registros de representación semiótica y el impacto que causan estos en el aprendizaje de nociones matemáticas. Un registro está constituido por signos como: trazos, símbolos, ícono, etc., los cuales se asocian de dos maneras, interna relacionada a las imágenes mentales que un individuo puede tener de un objeto; y externa, referentes a lo que éste puede percibir con los sentidos. Por consiguiente los registros son medios de expresión y de representación tales como notaciones algebraicas, gráficas o menciones verbales caracterizados por sus respectivos sistemas semióticos.

Las representaciones semióticas "son aquellas en las cuales la producción no puede hacerse sin el cambio o movilización de un sistema semiótico: así las representaciones semióticas pueden ser producciones discursivas (en lenguaje natural, en lenguaje formal) o no discursivas (figuras, gráficos, esquemas...)" [3]. Para tener mayor claridad sobre la producción de las representaciones semióticas Duval plantea tres aspectos en los cuales se enmarcan las intenciones, posibilidades e intereses que se persiguen a la hora de hacer uso de los símbolos. En primer lugar se encuentra la determinación de la importancia que tienen los signos y lo que estos pueden llegar a representar, en segundo lugar la fenomenología, referente a la aprehensión de los signos y el tercero está relacionado a la utilidad que prestan estos signos.

Es importante establecer diferencias entre un registro de representación y otro, al igual que establecer una coordinación entre registros de tal manera que se pueda extraer información de un mismo objeto matemático con diferentes registros de representación, esto se logra mediante la movilización de un registro a otro. Sin embargo se considera que no debe confundirse el objeto matemático con las representaciones del mismo, ya que si esto sucede un estudiante solo podría acceder a una parte del objeto matemático y no a su totalidad. Así como se menciona en [3], "la diferenciación funcional de registros de representación y la coordinación entre ellos constituyen los dos puntos clave para el aprendizaje".

Después de establecer algunas generalidades de esta teoría cognitiva y de adquisición, en el sentido en el que el sujeto es considerado como un sujeto cognitivo que accede al conocimiento matemático y aprende a través de una mediación semiótica, es preciso para este escrito profundizar en dos registros de representación, la lengua natural y el algebraico.

La actividad matemática necesita modos de funcionamiento cognitivo que requieren movilización de sistemas de representación semiótica, por ejemplo un problema de mezclas en su mayoría siempre es presentado en el registro lengua 
natural y se espera que el estudiante pueda resolverlo a partir de la información dada en el enunciado del problema; sin embargo si el estudiante no se sabe de memoria la ED lineal de primer orden que modela un problema de mezclas o si no se le proporciona, lo más probable es que no pueda resolverlo. Y es que el empleo del registro lengua natural en algunos dominios de la actividad matemática es fundamental, según [2] aunque se le conciba solo para enunciados de las definiciones o teoremas, estos obligan a considerar el empleo de otras expresiones simbólicas pertenecientes a sistemas semióticos desarrollados para tratamientos algebraicos, analíticos o formales.

\section{Materiales y métodos}

Esta propuesta se implementó a un grupo de 21 estudiantes de ingeniería civil de una universidad pública de Colombia inscritos en la asignatura de Ecuaciones Diferenciales en el segundo semestre del año 2012. El lugar donde se implementó la propuesta fue en una sala de informática, la cual cuenta con 25 computadores, todos con conexión a internet, y el software Java instalado y adecuado para la reproducción del material de apoyo virtual (software matemático). El tiempo que duró la implementación de la propuesta fue de dos días de clase. Es importante aclarar que en cada día de clase, el trabajo se desarrolló de forma individual y en un tiempo de dos horas. A cada estudiante se le entregó de manera impresa el material (para más detalles observar el anexo) y posteriormente se realizó la lectura del contenido de ese material, el cual está compuesto por tres actividades cada una acompañada de unas preguntas elaboradas, con el fin de guiar poco a poco al estudiante a plantear la ED lineal de primer orden que modela un problema de mezclas.

\section{Desarrollo de la propuesta y resultados}

En la solución de problemas de mezclas que son modelados por una ED se requiere que el estudiante tenga claridad en el manejo de la derivada como una razón de cambio, de tal manera que le permitiera identificar constantes, parámetros, y variables que dependen entre sí. Por tal razón, en la propuesta se contemplan tres actividades que el estudiante debe desarrollar con el fin de que logre plantear la ED que se ajusta al problema de mezclas dado, de tal forma que ésta no represente solo una expresión algebraica, sino que por el contrario, que esta expresión represente la visualización del suceso expresado en el registro lengua natural.

\subsection{Actividad 1}

Esta actividad tuvo como finalidad que los estudiantes identificaran razones de cambio, para ello se les recordó previamente que "La derivada expresa el cambio instantáneo que experimenta una variable con respecto a otra, para una función 
$y=f(x)$, se podría obtener la derivada o razón de cambio de las variables " $y$ " y

" $x$ " con respecto al tiempo " $t$ ", es decir: $\frac{d y}{d t} \mathrm{y} \frac{d x}{d t}$ ". En las cinco situaciones que se les planteaba, los estudiantes debían establecer la relación entre dos variables, por ejemplo cuando en la situación: "Cuando llenas un vaso con gaseosa, ¿qué tan rápido cambia el nivel de líquido al llenar el vaso?" Los estudiantes debían relacionar el enunciado con una expresión de la forma $\frac{d h}{d t}$ donde $h$ representa el nivel y $t$ el tiempo.

El $70 \%$ de los estudiantes obtuvieron un resultado aceptable al realizar la movilización del registro lengua natural al algebraico en al menos 3 de las 5 situaciones, el $30 \%$ restante solo tuvo éxito a lo más en 2 situaciones. También se observó que los índices más altos de fracaso al realizar la movilización de un registro a otro, se presentaron en las situaciones 4 y 5 con $81 \%$ y $76 \%$, respectivamente. Esto significa que los estudiantes identificaron razones de cambio en situaciones donde solo se aprecia una variable que depende del tiempo, sin embargo presentaron dificultad en situaciones donde se presenta más de una variable dependiente no necesariamente del tiempo.

\section{2. $\quad$ Actividad 2}

Esta actividad se dividió en dos partes, en la primera parte se continua haciendo énfasis en la identificación en el enunciado de la situación de la razón de cambio. La situación que se les plantea es: ¿Qué expresión algebraica describe la rapidez con la que sube el nivel $n$ de líquido en un tanque cilíndrico vertical de radio $r$, si llenamos aquel a una razón de $3 \mathrm{~m}^{3} / \mathrm{min}$ ? Con el apoyo de un software matemático el estudiante podía visualizar que a medida que el tiempo cambiaba, el nivel y el volumen del líquido en el cilindro también lo hacían. Además debían fijarse detalladamente en las características del registro en que fue formulado el problema, pues el mismo enunciado ya define la expresión en el registro algebraico para el nivel del líquido y para el radio del cilindro.

Luego de que los estudiantes exploraban con el software, se les formularon seis preguntas y se observó que el $34 \%$ fracasó en la movilización del registro lengua natural al algebraico. En la segunda pregunta el $52 \%$ respondió de forma incorrecta, esto se debe a que muchos cometieron errores relacionados a: identificar la dependencia e independencia de variables; considerar el volumen o nivel como variables; expresar constantes o parámetros como variables; y expresar una variable como un diferencial. Respecto a la pregunta 3, el $48 \%$ de los estudiantes no expresaron correctamente la función que relacionaba las variables, es decir, $V=\pi r^{2} h$, donde $V$ representa el volumen del recipiente, $r$ el radio y $h$ la altura. Esto se debe a errores asociados a la multiplicación, porque los estudiantes multiplicaron la variable tiempo por $\pi r^{2} h$ e incluso expresaron el volumen como una derivada. En la pregunta 4 el $71 \%$ fracasó en la solución debido a que algunos estudiantes no manejan la derivación implícita, no derivan la expresión $V=\pi r^{2} h$ con respecto al tiempo, ya que la variable no se encuentra en la expresión. Finalmente en las preguntas 5 y 6 los porcentajes de fracaso 
fueron de $57 \%$ y $81 \%$ respectivamente pero no fue posible realizar una lectura de los errores frecuentes, pues la gran mayoría dejó en blanco.

En la segunda parte de la actividad 2 se buscó acercar al estudiante a un tipo de razonamiento que debía desarrollar al resolver problemas de mezclas. Así que debía observar cómo se comporta la cantidad de líquido en un recipiente, cuando se tienen sus velocidades de entrada y salida. Para ello, se le presentó la situación en registro lengua natural: "Un tanque con forma de cono es llenado con agua a razón de $7 \mathrm{pies}^{3} / \mathrm{min}$, si la altura del tanque es de 12 pies, el radio de la base es de 6 pies, y el tanque posee un orificio en su parte inferior por el cual sale agua a una razón de $1 \mathrm{pies}^{3} / \mathrm{min}$, entonces responda:" y se le formularon seis preguntas. Antes de que los estudiantes respondieran estos seis interrogantes, ellos tenían tiempo para apoyarse en el software, el cual les permitía visualizar qué ocurría con la cantidad de líquido en el cono a medida que pasaba el tiempo. Se esperaba entonces que el estudiante lograra, con el desarrollo de esta actividad, realizar la movilización del registro en lengua natural al algebraico deduciendo que la cantidad de líquido en el tiempo $t$ se puede expresar como $C_{l}=\left(V_{E}-V_{S}\right) t$.

En las preguntas 1 y 6 , el porcentaje de fracaso fue del $67 \%$ y $71 \%$ debido a errores relacionados a la identificación de dependencia de las variables volumen o nivel, dependencia de las velocidades de entrada y salida con respecto al tiempo, y deficiencias en el proceso de derivación implícita. En las preguntas 2, 3 y 5 , el porcentaje de fracaso es de $48 \%, 39 \%$ y $43 \%$, respectivamente, debido a errores comunes como expresar la cantidad de agua como una razón de cambio, tener o no tener en cuenta la pertinencia de algunas variables, por ejemplo algunos no tuvieron en cuenta el tiempo como variable.

\subsection{Actividad 3}

Esta actividad se dividió en tres situaciones referentes a problemas de mezclas, pues se esperaba, de acuerdo al trabajo realizado en las actividades 1 y 2 , que el estudiante estuviera en condición de plantear la ED lineal de primer orden que permite modelarlos. Cada situación tiene apoyo de un software para que el estudiante pudiera visualizar el comportamiento de cada problema.

- Problema 1. A un tanque que contiene 300 galones de salmuera (es decir, agua en la que se ha disuelto cierta cantidad de libras de sal). Se vierte otra solución con una concentración de sal de 2 libras por galón, a una velocidad de 3 galones por minuto. Cuando la solución se mezcla bien en el tanque, se extrae al mismo ritmo que la solución de entrada. Encuentre la ecuación diferencial que modela este problema. Para llevar al estudiante a plantear la ED se formularon las siguientes preguntas:

1. ¿Cuáles son las variables de este modelo? Clasifícalas como dependientes e independientes. Se considera necesario que el estudiante identifique cuáles son las variables y en función de quién deben estar.

2. ¿Qué sucede con el nivel y el volumen del líquido, en cualquier instante de tiempo? Con esta pregunta se espera, que el estudiante centre su atención en la variable cantidad de sustancia; ya que en problemas donde 
las velocidades de entrada y salida del líquido son iguales, la cantidad de líquido en el recipiente y el nivel permanecen constantes.

3. ¿Cómo cambia la variable dependiente en función de la variable independiente? Pregunta que orienta al estudiante a representar en el registro algebraico que el cambio de la variable dependiente en función de la variable independiente viene dada por la expresión $C_{l}=\left(V_{E}-V_{S}\right) t$.

4. ¿Qué cantidad de sal entra en cualquier tiempo? Debido a que no se dan de forma explícita las velocidades de entrada y salida de sustancia, se espera que realicen este proceso de conversión.

5. ¿Qué proceso debes realizar para responder: qué cantidad de sal sale del tanque en cualquier instante de tiempo? Con esta pregunta el estudiante debe darse cuenta que cuando en un recipiente se tiene disuelta una cantidad de - sustancia la cual se desconoce y que además se le agrega más sustancia para mezclarla de forma uniforme y sacarla del recipientese debe dividir la cantidad de sustancia que se encuentra en el recipiente entre el volumen para determinar la cantidad de SAL que sale del tanque en cualquier instante de tiempo.

6. ¿Con qué velocidad cambia la cantidad de sal en cualquier instante de tiempo? Desde la primera actividad se está trabajando el proceso de movilizarse del registro lengua natural al algebraico, con el propósito de que al abordar este tipo de problemas los estudiantes tengan herramientas para realizar la movilización de registro.

En este problema se pudo observar que la implementación muestra un desempeño aceptable por parte de los estudiantes, ya que después del trabajo realizado en las actividades anteriores y las retroalimentaciones correspondientes, se encontró que en la pregunta 1 solo el $17 \%$ no tuvo éxito. Ahora bien, respecto a la pregunta 2 y 4 se encontró un porcentaje de éxito del $100 \%$ y en las preguntas 5 y 6 del $72 \%$. Respecto a la pregunta 3 en la que debían realizar una movilización de registros, el $67 \%$ aunque acertaron en la respuesta, no realizaron la movilización entre registros y la formularon en el mismo registro, lengua natural.

- Problema 2. Se considera un tanque que contiene azúcar y agua con los que se prepararán refrescos embotellados. Suponga que el tanque contiene 100 galones de líquido, la cantidad que fluye hacia adentro es la misma que fluye hacia afuera, pero siempre hay 100 galones en el tanque. El tanque se mantiene bien mezclado, por lo que la concentración de azúcar es uniforme en todo el tanque. El agua azucarada que contiene 5 cucharadas de azúcar por galón, entra al tanque a través del tubo $A$, a razón de 2 galones por minuto. El agua azucarada que contiene 10 cucharadas de azúcar por galón, entra al tanque a través del tubo $B$, a razón de 1 galón por minuto. El agua azucarada sale del tanque a través del tubo $C$ a razón de 3 galones por minuto.

Este problema aunque pareciera diferente al primero difiere en el registro de lengua natural, son enunciados diferentes, sin embargo es un problema de mezclas en el que la velocidad de entrada y salida de líquido son iguales, por lo que el volumen permanece constante y por consiguiente cuando los 
estudiantes realizan la movilización al registro algebraico llegaran a la misma ED que modela el problema 1. Aunque las preguntas que se les formulan a los estudiantes son iguales a las del problema anterior, se les realiza una más y es la siguiente: ¿Qué cantidad de azúcar entra en total al tanque en cualquier momento $t$ ? Esta pregunta tiene como objetivo facilitar que el estudiante visualice que la cantidad de agua, y por ende de sustancia que entra al tanque, es el resultado de la suma de las velocidades de entrada de sustancia por cada tubo.

En este problema los estudiantes realizaron correctamente la conversión de unidades de media y a pesar de cambiar las condiciones de llenado del tanque, interpretaron la velocidad de entrada de líquido como la suma de las velocidades de entrada en cada tubo. De la misma forma que en el problema anterior en la pregunta 3, el porcentaje más alto de fracaso fue en la pregunta 2 con un $67 \%$, ya que a pesar de que dieron la respuesta correcta no la formularon en el registro algebraico.

- Problema 3. Un tanque grande de mezcla inicialmente contiene 200 galones de agua disuelta con $50 \mathrm{Lb}$ de sal (salmuera). Otra solución de salmuera se inyecta en el tanque a una velocidad de 3 galones por minuto; en este flujo de entrada, la concentración de sal es de 2 libras por galón. Cuando la solución se mezcla bien en el tanque, se extrae a una velocidad de 2 galones por minuto. Si el tanque tiene tapa abierta y una capacidad total de 300 galones, responde: ¿En qué tiempo se derramara el líquido?, ¿Cuántas libras de sal habrá en el tanque al instante del derrame?. Grafique la solución en un software y comente acerca de cuántas libras de sal hay en el tanque cuando $t \rightarrow \infty$. ¿Coincide con lo que usted creería sin haber hecho ningún proceso?

Este problema es mucho más complejo con respecto a los dos problemas anteriores y se espera que para su solución el estudiante haga uso de todos los procesos trabajados a lo largo de estas tres actividades, resaltando entre estos, el proceso de la interpretación de la variación presente en un problema de mezclas y la movilización del registro lengua natural al algebraico.

En este problema se observó que el $67 \%$ de los estudiantes plantearon la ED lineal de primer orden, obteniendo así éxito en la movilización del registro lengua natural al algebraico y aunque las preguntas de este problema diferían con las de los 2 problemas anteriores se esperaba que sirvieran al estudiante como herramienta para plantear la ED que modelaba el problema dado.

\section{Discusión}

Se encontraron deficiencias en el manejo de los diferenciales y de la derivación implícita. No tener claro estas fórmulas matemáticas impiden que el estudiante realice correctamente la movilización del registro lengua natural al algebraico.

De acuerdo a lo analizado en los problemas 1 y 2 de la actividad 3, los estudiantes tienen una fuerte tendencia a expresar la respuesta en el registro de 
representación en que se le es formulada la pregunta, en este caso la respuesta que dieron fue en lengua natural cuando se esperaba que dieran la respuesta en el registro algebraico. Esto coincide con [3] donde se menciona que "las respuestas se quedan en el registro en el cual está planteada la pregunta".

El apoyo de un software es importante ya que se convierte en un puente para la movilización de un registro a otro, permitiéndole al estudiante identificar algunas características que posiblemente no se visualicen en un registro.

El planteamiento de una ecuación diferencial lineal de primer orden que modela un problema de mezclas, depende entonces de las mediaciones semióticas que se utilicen para realizar la movilización del registro lengua natural al algebraico como bien se pudo observar en cada pregunta formulada.

\section{Referencias}

1. De las Fuentes Maximiliano, Arcos L. José, Navarro R. Carlos.: Impacto en las Competencias Matemáticas de los Estudiantes de Ecuaciones Diferenciales a Partir de una Estrategia Didáctica que Incorpora la Calculadora. Formación Universitaria, Vol. 3(3), 33-44. (2010).

2. Duval, Raymond.: Un tema crucial en la educación matemática: La habilidad para cambiar el registro de representación. La Gaceta de la RSME, Vol. 9.1, 143-168. (2006).

3. Guzmán, Ismenia.: Registros de representación, el aprendizaje de nociones relativas a funciones: voces de estudiantes. Relime, Vol. 1, Núm. 1, 5-21. (1998).

4. Morales L. Yuri, Salas H. Oscar.: Incorporación de la tecnología para la enseñanza y aprendizaje de las ED ordinarias. Cuadernos de Investigación y Formación en Educación Matemática, 6, 155-172. (2010).

5. Nápoles Valdés, J. E., González Thomas, A., Brundo, J. M., Genes, F., Basabilbaso, F.: El enfoque histórico problémico en la enseñanza de la matemática para ciencias técnicas: el caso de las ecuaciones diferenciales ordinarias. Acta Scientiae, 6, 41-59. (2004).

6. Zill Dennis, Cullen Michael.: Matemáticas avanzadas para ingeniería, Vol 1. Ecuaciones diferenciales Tercera Edición, Editorial McGraw-Hill. (2008). 